\title{
O outro: análise crítica de discursos sobre imigração e gênero'
}

\author{
llana Mountian ${ }^{a, b^{*}}$ \\ Miriam Debieux Rosa ${ }^{a, c}$ \\ aUniversidade de São Paulo, Instituto de Psicologia, Departamento de Psicologia Clínica. São Paulo, SP, Brasil \\ ${ }^{b}$ Manchester Metropolitan University. Manchester, Reino Unido. \\ cPontifícia Universidade Católica de São Paulo (PUC-SP), Núcleo Psicanálise e Política. São Paulo, SP, Brasil
}

\begin{abstract}
Resumo: Esse artigo teve como objetivo desenvolver uma análise crítica de discursos sobre imigração e a posição que alguns imigrantes ocupam no discurso social. O foco é dado nos processos de minorização de alguns grupos, destacando a questão de gênero sem deixar de considerar as intersecções entre sexualidade, raça e classe social, conforme a tradição dos estudos críticos feministas e pós-coloniais. Neste sentido, examinamos alguns fragmentos de casos de imigrantes recém-chegados em um grande centro urbano, São Paulo. A posição em relação ao imigrante, como representante da alteridade, nos permitiu levantar algumas considerações, tendo como operadores a teoria da psicanálise, de Foucault e de estudos feministas e antirracistas. Nos casos apresentados, nota-se que o próprio processo de imigração muitas vezes não é levado em consideração na relação com o imigrante, o que pode naturalizar as diferenças sociais como traços individuais patologizados quando não criminalizados. Diversas posições dentro do imaginário social são ressaltadas e vividas nas relações com imigrantes. Ainda que com suas especificidades, pode-se ressaltar que uma série de discursos sobre imigrantes são continuamente reiterados colocando-os muitas vezes nas posições de vítimas, ameaças ou seres exóticos. Partindo dessa reiteração discursiva, analisamos como o outro é constituído nesse discurso, muitas vezes aparecendo como um outro fetichizado. Essa análise visou promover pontos críticos para intervenções e políticas públicas.
\end{abstract}

Palavras-chave: imigração, gênero, psicanálise, análise de discurso, teorias críticas.

\section{Introdução}

Esse artigo tem como objetivo desenvolver uma análise crítica de discursos sobre imigração e a posição discursiva muitas vezes estática que alguns imigrantes ocupam nesses. $\mathrm{O}$ foco foi dado nos processos de minorização de alguns grupos, ressaltando em particular as intersecções entre gênero, sexualidade e raça. É visto, portanto a formação do outro no discurso dessas dinâmicas imigratórias.

Esse é um tema que incorpora uma série de complexas relações e requer análises que proporcionem uma visão multifacetada do fenômeno. Dessa forma, nessa perspectiva crítica, ou seja, uma desconstrução de discursos sobre a imigração considerando as relações de poder, o artigo parte de contribuições dos estudos feministas, pós-coloniais e foucaultianos na interface com a psicanálise. Este sendo um campo importante para o desenvolvimento de pressupostos teóricos para análises interseccionais considerando as relações entre sujeito e sociedade e, em particular, do sujeito enquanto intrinsicamente social, constituído a partir da linguagem. Nesse sentido, aspectos desse debate serão levantados no artigo, focando nas contribuições da psicanálise para a formulação do outro/Outro. Um aspecto importante nesse desenvolvimento é o entendimento das dinâmicas sociais e políticas considerando as intersecções

1 Pesquisa realizada com o apoio da FAPESP.

* Autora correspondente: imountian@yahoo.com entre psicanálise e política, crucial para a desconstrução da própria posição discursiva sobre o imigrante.

Há muitos tipos de processos imigratórios e é necessário considerar a história de cada um e a sua recepção no país de chegada. Neste trabalho examinaremos alguns casos de imigrantes recém chegados em um grande centro urbano, a cidade de São Paulo, Brasil. Essas reflexões partem da nossa observação e intervenção em um projeto desenvolvido no Fundo de Cultura e Extensão Universitária da Universidade de São Paulo, "Migração e Cultura: experiências de atendimento a pessoas em situações de vulnerabilidade psíquica e social", fazendo parte das atividades do Laboratório Psicanálise e Sociedade do IP-USP e do Núcleo de Estudos e Pesquisa Psicanálise e Política do Curso de Pós-graduação de Psicologia Social da PUC-SP.

Nas intervenções propostas, a problematização da articulação sujeito e enlaçamento social é tida como fundamental, o que nos lança na perspectiva da psicanálise implicada, ou seja, "aquela constituída pela escuta dos sujeitos situados precariamente no campo social que permite teorizações sobre os modos como são capturados e enredados pela maquinaria do poder" (Rosa, 2013, p. 30). Considera-se, portanto, que

essa articulação visa evidenciar os efeitos, por vezes trágicos, do modo em que o discurso social e político, carregado de interesses e sede de poder se 
traveste de discurso do Outro (campo da linguagem) para capturar o sujeito em suas malhas... . O discurso social contemporâneo se trasveste como um discurso hegemônico, referido à lei do mercado, aparentando consistência e a-historicidade que obscurecem seus interesses na manutenção sócio-política. (Rosa, 2013, p. 35)

Essa articulação no campo do político ressalta dois âmbitos primordiais, junto ao sujeito e junto às instituições e seus discursos, dimensões indissociáveis. É na análise dos efeitos discursivos no sujeito que esse artigo terá seu foco.

\section{O outro na imigração}

Esse artigo traz algumas contribuições críticas ao debate atual sobre imigração. Para isso, centramos a análise na noção do "outro", que, nesse caso, evidencia muitas vezes a posição discursiva sobre o imigrante.

Sendo assim, torna-se importante primeiro uma breve exposição da elaboração da noção do outro a partir de algumas perspectivas teóricas, no caso, da psicanálise, Foucault e estudos feministas e anti-racistas para então partirmos para a análise proposta.

\section{O outro/Outro psicanalítico}

Lacan (1966/1998; Lacan (1968-1969/2008) elabora a noção do outro a partir de Freud $(1905,1919,1921)$, enquanto aquele constitutivo do sujeito. Para isso Lacan desenvolve a distinção entre o outro (petit autre) e o Outro (o grande Outro, Autre). Essas posições corresponderiam às dimensões imaginárias e simbólicas na teoria de Lacan, dimensões que se encontram relacionadas também em relação à dimensão do real (Neill, 2011).

O reconhecimento do si mesmo passa pelo outro especular, a fim de reencontrar, de reconstituir o objeto causa de seu desejo. Segundo Chatelard (2001), "desde Freud, o termo imagem - Bild - e sua função primordial entre o sujeito e seu semelhante já tinha um lugar importante na constituição do sujeito. Com Lacan, uma passagem se efetua entre a imagem, tal como foi concebida por Freud, e o que resta dessa imagem como não especular” (p. 341).

A constituicão do outro para Lacan está relacionada à dimensão especular, ou seja, às relações duais. Relação desenvolvida no estádio do espelho, incorporando a ilusão da Gestalt e completude do sujeito, identificação e relação com o outro (Lacan, 1966/1998). Rosa e Cerruti (2014) ponderam que

há, então, que se considerar o lugar do semelhante na estrutura de um sujeito, lugar esse mais além de ele ser um possível rival. Sabemos que o sujeito se inscreve em uma topologia que não possui interior nem exterior e o que determina a representação de um sujeito em cada contexto é a maneira como o outro me reconhece ou não, me legitima ou não. Isso porque o desamparo estrutural do homem supõe uma relação de dependência desde o princípio. A existência do outro, seus cuidados e sua voz, são condições necessárias, pois é por meio de tais cuidados que a demanda de amor pode vir a engendrar o objeto de desejo. (p. 13)

Lacan (1968-1969/2008) aponta no Seminário "Do Outro ao outro", que "o próximo é a eminência intolerável do gozo" (p. 219). O que está em pauta nessa suposição é o suporte de uma presença que tanto pode ser obstáculo como viabilizadora, impedimento ou passagem para a sobrevivência do bem comum.

O Grande Outro é o referente à relação simbólica, relacionado à rede simbólica regulada com regras de linguagem e, como uma estrutura psíquica, o Outro seria o representante desse social, internalizado em forma do inconsciente (Grosz, 1990). O encarregado da inserção da criança no campo do Outro, caracterizando como Outro primordial é a "mãe", não necessariamente a mãe biológica, mas alguém que opere como agente ocupando a posição que oferece os significantes para a criança que pode se articular ao desejo do Outro. Falta e desejo são articulados, de modo que a falta causa desejo, pois a falta no simbólico é a falta no Outro, referente ao desejo do Outro (Verhaeghe, 1997). O universo dos significantes ficam atrelados ao desejo da "mãe", sua historia e de sua comunidade - o campo do Outro é inapreensivel a não ser a partir destas bordas com o discurso, permeadas do registro histórico e imaginário de um dado tempo e lugar.

Alguns autores levantam questões sobre a relação com a falta e a posição do feminino na cultura. Frosh (1995) elabora a afirmação de Lacan "A mulher não existe", como relacionada à posição de "mulher", onde essa é entendida então como a (não) posição simbólica. Segundo ele,

Lacan aponta que a organização da cultura essencialmente patriarcal, ou mais especificamente a estrutura fálica da linguagem, significa que a mulher toma o seu lugar como o Outro, como algo que se localiza fora do simbólico como seu negativo, tendo sua presença através de sua exclusão" (Frosh, 1995, p. 291)

Fora da estrutura fálica da linguagem significa também fora do poder. Porém, é importante apontar que o significante não está isolado da linguagem, mas dependente de todo o sistema de significados. Nesse sentido, Frosh (1995) aponta que, "não apenas historicamente, em relação à função reprodutiva, mas também continuamente, em relação ao seu impacto na ordem das coisas - simbólico assim como imaginário - a [posição da] mulher faz o masculino existir" (p. 293).

\section{Posições discursivas do Outro}

Uma série de autores discute a questão do Outro em relação à posição simbólica e à formação de regimes de 
diferença, em especial o debate para a análise de relações desiguais, como em relação ao racismo e ao sexismo.

Foucault (1991), em sua análise sobre mecanismos de poder elabora a relação entre o "olhar" normalizante e a formação do outro objetificado, ou seja, centra na relação da mirada com o outro visto como "objeto". A partir dos modelos do "panopticon" e da "peste", o outro pode ser identificado como ocupando duas posições polarizadas em discurso, que são da "vítima" e "peste". A peste é vista aqui como correspondente à posição discursiva do outro como "estranho", "inimigo", "ameaça" (Chomsky, 1991).

Por essa perspectiva do outro, "diferença" surge como uma palavra chave para intervenção crítica, ou seja, relacionada à formação do outro concebido como "aquele que é diferente de nós".

Nas discussões acadêmicas e de políticas públicas, alguns enfoques promovem a produção desse outro na sua positividade, através de estratégias envolvidas em "celebração da diferença". Porém, mesmo o outro na sua positividade, tem sua posição discursiva do outro mantida. Badiou (2001) fornece um relato crítico do "direito à diferença", onde a ética dos direitos humanos parece definir uma identidade, e dessa maneira, o respeito ao diferente é aplicado somente àqueles que são "razoavelmente consistentes com essa identidade" (p. 24). Dessa maneira, Badiou questiona: "o celebrado "outro" só é aceito se ele for um bom outro - o que quer dizer, exatamente o mesmo que nós mesmos?" (p. 24).

Outra frente discursiva sobre a posição do outro pode ser vista nos discursos do multiculturalismo - estudos críticos apontam como, mesmo a partir da perspectiva multicultural, o "imigrante" continua ainda sendo visto como o outro em discurso (Gilroy, 2000; Silva, 2000; Balibar, 1991; Žižek, 1998). Žižek (1997/2005, citado por Ramos, 2009) discute o racismo atual como sintoma do capitalismo multicultural, onde a tolerância neo-liberal anula a diferença do outro, que é rapidamente tido como "fundamentalista", pois a alteridade reside na regulação do próprio gozo.

Ou seja, em ambas as estratégias e discursos do outro como diferente (celebração da diferença e multiculturalismo) ou do outro como igual (anulando a diferença), temos a posição discursiva do outro reiterada, ou seja, posicionando o outro como estranho (estrangeiro), em seus hábitos, caráter ou saúde mental, inimigo ou exótico.

Nos estudos feministas e queer, a noção do outro é elaborada e utilizada em relação à gênero (Burman, 2000) e sexualidade (Gordo-López, 1995). Butler (1998) desenvolve, nesse sentido, a temática do abjeto, ao se referir às sexualidades fora da norma, ou seja, ininteligíveis, que fogem às normas hegemônicas da direta relação entre gênero, sexualidade, prática sexual e desejo.

O outro aqui não será considerado apenas em relação à posição do excluído no discurso, mas também como constitutivo da norma. O outro, portanto, também cria o espaço discursivo que define o que somos nós.

Nos estudos críticos feministas e pós-coloniais sobre a noção do outro, essa perspectiva do espaço discursivo para a demarcação de quem somos nós, é fundamental. McClintock (1995) em seu trabalho sobre o fetichismo nas relações coloniais europeias, discute o modo como o objeto-fetiche veio a simbolizar a divisão entre nós e o outro. Fetiche, do português feitiço, era o nome usado para amuletos durante o período colonial, simbolizando ao mesmo tempo encantamento e ameaça. Nessa elaboração McClintock mostra como o fetiche serviu para estabelecer o que era moderno e o antigo, retrógrado, próprio das colônias na visão dos europeus, ajudando a estabelecer a própria noção de progresso do iluminismo. Torna-se, portanto, fundamental o entendimento do "encontro" para a formação do outro e do nós.

As terras fetichizadas da África incorporaram um necessário universo de erros contra o qual o iluminismo podia mediar seu imponente progresso: erros de lógica, de racionalidade analítica, de julgamento estético, de progresso econômico e de legitimidade política. ("tradução nossa") (Mc Clintock, 1995, p. 187)².

Fetichismo, portanto, neste contexto teórico está relacionado a conflitos de valores "culturais". Participa na produção discursiva do que era então visto como moderno, positivo e desenvolvido e determinando o que não era familiar para o europeu como negativo, negado e desviante. $\mathrm{O}$ encontro produz o espaço para a modernidade, o encontro produz ambos: "eles" e "nós" (Mountian \& Gonzalez, 2011).

Ahmed (2000) discute a noção da diferença a partir da figura do estrangeiro (desconhecido, stranger), onde esse é normalmente visto como ameaça ou como aquele que demarca a diferença. Ahmed debate como as afirmações de que todos nós somos "estrangeiros" (strangers), não é suficiente para a questão, uma vez que "alguns outros são designados como mais estrangeiros (estranhos) que outros" ("some others are designated as stranger than other others", p. 6, tradução nossa). Aqui é essencial a contextualização do encontro, no caso entre o imigrante e o lugar de chegada. Para isso, Ahmed sugere que para evitar o "fetichismo do estranho", é necessário interrogar as relações sociais que estão na fundação de tais encontros, "relações sociais que são ocultadas por esse exato fetichismo" ("social relationships that are concealed by this very fetishism", p. 6, tradução nossa).

Quais seriam, portanto, as possibilidades desse encontro? Como o outro é formado nessas relações?

\section{Discursos sobre imigração imigrantes}

Nesse sentido, torna-se relevante apontarmos alguns dos discursos sobre imigrantes na contemporaneidade. É claro que aqui temos alguns recortes específicos e em

\footnotetext{
2 "The fetish-lands of Africa embodied a necessary universe of errors against which the Enlightenment could measure its stately progress: errors of logic, of analytical reasoning, of aesthetic judgement, of economic progress and of political legitimacy"
} 
hipótese alguma há a intenção em generalizar tais discursos. Porém, a posição do imigrante em relação à alteridade nos permite levantar algumas considerações, em especial em relação - que queremos demonstrar - à objetificação do outro, e muitas vezes da reificação do outro em discurso.

Tais posições reiteradas muitas vezes como estáticas e sem modulacão têm efeitos discursivos importantes na relação com o imigrante, assim como nas políticas públicas voltadas ao imigrante, como veremos mais adiante.

As observações que realizamos vêm em parte dos encontros que se deram na Casa do Migrante que abriga pessoas de diversos lugares do mundo, diferentes línguas, diversas religiões e credos. O objetivo da Casa é acolher migrantes, sem distinção de sexo, etnia, cor, credo, nacionalidade ou qualquer outra forma passível de discriminação. É um abrigo referenciado na filosofia de trabalho da Missão Escalabriniana e gerido por uma entidade católica, a Missão Paz. Os imigrantes que chegam a São Paulo e estão neste abrigo transitam também pela Caritas Arquidiocesana de São Paulo, Centro de referencia para refugiados.

\section{Fragmentos de casos}

Para a análise parte-se de três fragmentos de casos: uma família boliviana composta pelo pai e três filhas, para refletir sobre as relações de imigração e gênero; um imigrante jovem russo, onde a relação entre psiquiatria e cultura é exposta; e o caso de uma travesti, refletindo sobre os efeitos da transfobia e as relações entre trans-corpos e trans-nacionalizações, corpos sem espaço. Estes exemplos servirão de base para a análise da/o migrante quando ocupa a posição discursiva do outro, como veremos adiante.

\section{Família, gênero e nação - Fragmento 1}

No caso da família boliviana, uma série de aspectos serão levantados - em particular propõe-se uma análise do entendimento localizado de família e gênero que são colocados em questão, uma vez que nas relações do pai com os serviços públicos, a impossibilidade do seu cuidado em relação às filhas é sempre exposto. Aqui a intenção não é o julgamento sobre a possibilidade do cuidado, mas como ideias sobre as posições sociais baseadas em gênero impactam nas concepções de família e imigração.

A noção de família é um elemento fundamental para a ideia de nação, que compõe integralmente o âmbito da imigração. McClintock (1995) aponta que

a família ofereceu uma figura metafórica indispensável pela qual diferença nacional poderia se dar forma numa narrativa de gênese histórica singular. Porém, um curioso paradoxo emergiu. A família como uma metáfora ofereceu uma narrativa de gênese singular para a história nacional enquanto que, ao mesmo tempo, a família como uma instituição tornou-se void (vazio) da história excluída do poder nacional. A família tornou-se, de uma vez e ao mesmo tempo, ambas a figura que organiza para a história nacional e sua antítese. (p. 357)

No caso citado, a ausência de uma figura feminina, coloca em xeque a legitimidade da "família", trazendo duas direções no argumento: primeiro questiona a posição do pai em relação à família, em particular em relação às suas atribuições e possibilidade de cumpri-las, e segundo, a ideia de que a filha mais velha, que não é tão "velha", deva ter a incumbência em cuidar da família, responsabilidade que é compartilhada em vários contextos, visto tradicionalmente como função feminina.

Portanto, é possível apontar que mulheres ocupam uma posição discursiva específica, normalmente vistas como representantes da ordem social, as "guardiães" da moralidade da sociedade, tendo os papéis sociais tradicionais de mães e cuidadoras. Yuval-Davis (1997) afirma que mulheres "reproduzem as nações biologicamente, culturalmente e simbolicamente" (p. 2). Entretanto, essa é uma posição paradoxal na qual ainda que as mulheres sejam essencialmente parte da nação, elas não são inteiramente incluídas no campo político, e a esfera privada não é considerada politicamente relevante. McClintock (1995, p. 359) faz um argumento similar: "mulheres são tipicamente construídas como symbolic bearers (portadoras simbólicas) da nação, mas são impedidas de qualquer relação direta à agenda nacional". Portanto, ao mesmo tempo que as mulheres estão localizadas fora dos campos público-político, elas são as representantes das moralidades culturais, elas reproduzem, mantém e simbolizam a "pátria mãe", guardiãs da moralidade, em particular mulheres mais velhas, e reproduzem homens racializados e nacionalizados.

\section{Saúde mental e imigração - fragmento 2}

No caso do jovem russo e seus encontros com os serviços públicos de saúde, pode-se levantar algumas questões em relação à vertente do outro/imigrante patologizado nas suas manifestações, disposição que apareceu na relação com a psiquiatria. Aqui podemos já apontar que assim como a história do sujeito, a própria psiquiatria que deve ser contextualizada culturalmente, socialmente e politicamente, em particular na relação com o imigrante. Nesses encontros, os fatos do imigrante gritar muito e se recusar a tomar banho foram rapidamente vistos como sintomas psiquiátricos. Como já apontado acima, não é intenção entrar no mérito do diagnóstico, mas analisar como aspectos culturais estão imbricados nas relações. Nesse caso, a rapidez da análise coloca em evidência a importância em se considerar elementos culturais e os processos imigratórios, para não disseminar uma visão que apaga diferenças ou, mais que isto, evitar a rápida classificação patológica de sujeitos que se encontram em situações de vulnerabilidade.

Em relação à imigração e saúde mental no Brasil, é apontado aqui a necessidade do desenvolvimento de estudos na área, em termos qualitativos e quantitativos. 
Enfatiza-se a importância em se considerar as condições sociais para o diagnóstico de problemas mentais. No caso citado, não foram considerados os contextos sociais e históricos do jovem russo, apontando para a necessidade de um entendimento mais aprofundado das complexidades clínicas acompanhando as condições culturais e de deslocamentos (Littlewood \& Lipsedge, 2001).

Há aspectos específicos que são fundamentais para se considerar nesse sentido, tais como as práticas religiosas, como bem exemplificado por Littlewood e Lipsedge (2001), condições excepcionais (como guerra) e seus efeitos (ex: medo de perseguição e autoridade), gênero (por exemplo mulheres podem estar mais isoladas socialmente e também com menos contato com a língua falada no local), efeitos do racismo e discriminação, entre outros.

É crucial, portanto, questionar como gênero, classe, raça, idade e cultura, entre outras categorias, configuram dentro dessas práticas discursivas. Phoenix (1987) denominou a "ausência normalizada e presença patologizada" dos imigrantes nos serviços públicos ingleses que, nesse caso, serve bem para exemplificar a maneira que "cultura" é compreendida. É comum, nesse sentido, que condições excepcionais (como guerra, fome, asilo) em intersecção com essas categorias chaves sejam vistas como características essenciais do outro, e não como exceção, onde saúde mental pode ser normalizado como um elemento cultural (Mountian, 2005).

Dois aspectos são apontados aqui: 1- saúde mental/ doença mental é vista como uma condição naturalizada ao invés de efeitos do racismo e circunstâncias excepcionais, como se o sujeito vivesse num vácuo social; e 2- preocupações em relação aos diagnósticos psiquiátricos e a prescrição de drogas psicotrópicas são levantadas. Primeiro, como já apontado, são ainda necessários estudos sobre as especificidades dos imigrantes; segundo, revisão dos diagnósticos psiquiátricos; terceiro, como visto em pesquisas anteriores (Mountian, 2005) circunstâncias específicas ligadas à imigração e asilo humanitário como, documentos, mudança, racismo, separação da família etc. podem ser bastante extenuantes, onde, depressão, por exemplo, não pode ser visto como algo dos imigrantes, mas, ao invés disso, considerar também como uma "resposta" a essas circunstâncias vividas e a administração de anti-depressivos e outras medicações psiquiátricas devem ser vistas com cuidado, podendo ter um impacto no sujeito no sentido de alienação.

Portanto, é fundamental o entendimento de como "cultura" é utilizada em discurso, visto que é normalmente usada com um significado específico ou incorporando pessoas de uma área geográfica específica. Uma perspectiva mais ampla é necessária, pois pessoas advindas de uma mesma região geográfica podem de fato ter muito pouco em comum (por exemplo, vindas de diferentes contextos políticos e sociais, diferenças de raça, classe, gênero, religião, linguagem etc). Cultura não é um termo fixo e precisa ser olhado em relação à cultura local. O que constitui cultura e o que é entendido por raça deve ser socialmente e politicamente contextualizado, assim como as relações de poder que constituem "outros" específicos.

Como Ahmed (2000) aponta ao discutir a construção de estrangeiros (estranhos, strangers) como aqueles que saíram de casa: "Nesse tipo de construção, os strangers são aqueles que, ao sair de casa da sua nação são os corpos fora de espaço (bodies out of place) no cotidiano no mundo o qual habitam e nas comunidades as quais eles vieram a viver" (p. 78) ${ }^{3}$. A partir dessa ideia de corpos fora de espaço, pode-se refletir sobre o fragmento 3, do corpo trans visto como um corpo fora de espaço também na sua própria casa.

\section{O outro sexualizado - Estudo de caso 3}

Em pesquisas anteriores (Mountian, 2012) foi levantada a história de algumas travestis nas quais os temas da violência e exclusão foram ressaltados desde a sua adolescência até o momento atual. Exclusão que se deu nos âmbitos da escola, família, bairro, cidade, trabalho e na própria utilização dos espaços públicos.

É importante apontar que gênero é conceitualizado em relação aos entendimentos prevalecentes de gênero em contextos sociais específicos. Comumente gênero sexual é saturado de uma gama de discursos do que é considerado "normal", "natural", em termos biológicos. É fundamental, portanto, apontar que seus entendimentos e performances decorrem de relações de poder dentro de contextos sociais e históricos. Dessa maneira, até os entendimentos biológicos de gênero devem ser contextualizados socialmente, por exemplo, como sabido, tradicionalmente na biomedicina ocidental, mulheres eram vistas como menos capazes de desenvolver funções de trabalho importantes e mais aptas ao trabalho doméstico devido à sua biologia (Rohden, 2003). Discursos sobre loucura, emocionalidade, e dependência tiveram um papel importante nesse contexto (Engel, 1997; Mountian, 2013), normalmente colocando-as como inferiores socialmente. Portanto, o que é enfatizado aqui são as atribuições, ideias, posições sociais que são destinadas ao gênero que estão em questão.

Nesse sentido, entendimentos sobre gênero e também sexualidade são vistos como performativos, como Butler (1999) desenvolve. Porém,

isso não significa que não há corpos, mas sim que como os corpos performam é (re)produzido e construído socialmente. Nesse sentido, não há uma necessária relação linear, causal ou coerente entre gênero, sexo, prática sexual e desejo. Gênero é performado através das normas de inteligibilidade, que são construídas historicamente e culturalmente. (Mountian, 2013, pp. 20-21)

Performatividade se refere à reiteração de normas, $\mathrm{e}$, nesse caso, de normas heterossexuais. Patriarcado refere-se

3 "In such a construction, the strangers are the ones who, in leaving the home of their nation, are the bodies out of place in the everyday world they inhabit, and in the communities in which they come to live". 
ao poder político (Pateman, 1993), apesar da invisibilidade desse entendimento na política. Explicitando a posição política social das mulheres, como de subordinação, por exemplo, e dos homens e da organização social como, por exemplo, contratos maritais (Pateman, 1993).

Nesse contexto, é possível identificar algumas hierarquias de gênero específicas baseadas nas concepções binárias de gênero e, focando na sexualidade, é possível apontar que esse terreno é heterossexualmente normativo, ou seja, aqueles comportamentos que não são considerados heterossexuais são altamente regulados e controlados.

Homofobia e transfobia são vistas como uma produção de relações de poder dentro de contextos sociais e políticos específicos (considerando também as relações com outras categorias sociais, como raça, idade e outros). Portanto, como as relações de gênero são concebidas, suas concepções binárias e heteronormativas, são elementos intrinsicamente conectados com o modo como a homofobia e transfobia são conceitualizadas e colocadas em operação. Dessa maneira, como a homofobia, a transfobia não está apenas relacionada ao preconceito contra pessoas LGBT mas também contra todas as pessoas que desafiam em alguma medida as normas heterossexuais (Junqueira, 2007).

No caso da travesti brasileira, o que vemos é que a transfobia institucionalizada nas relações cotidianas, formam a base para as diversas migrações vividas, tanto no Brasil quanto no exterior. Assim, é ressaltado como as relações de poder baseadas nas identidades de gênero, na sexualidade, impactam no campo da imigração. Ainda, e intrínseco a essa posição, impactam também as relações de classe e raça, questões cruciais para o entendimento dessas dinâmicas sociais. No caso das travestis, a hipersexualicão dos seus corpos.

Nos casos acima levantados, nota-se que o imigrante ocupa determinadas posições sociais em diversas modalidades do imaginário social que são ressaltados e vividos nas relações entre o eu e o outro (imigrante). Ainda que com suas especificidades, pode-se ressaltar quando a imigração não é considerada, muitas vezes naturalizando-se as diferenças sociais e por outro lado, quando o imigrante é visto, esse aparece com imagem estática, tendo sua posição do outro demarcada, mais especificamente um outro fetichizado, reiterado em discurso.

Esta questão toca aos imigrantes, embora não somente a eles. A posição discursiva sobre o imigrante como o outro é, então, comumente reiterada enquanto peste ou inimigo (ameaça), vítima, exótico ou anulando a diferença - o outro como nós. Os discursos apontados devem ser vistos em relação à produção e reprodução do posicionamento reificado do outro.

Torna-se, portanto, importante questionar outras possibilidades discursivas para o imigrante. Há alguma maneira de escapar essas posições discursivas?

\section{Considerações finais}

Os exemplos citados servem para apontar a importância da constante reflexividade na relação das instituições com os imigrantes, sendo fundamental considerar os processos migratórios e de vulnerabilidades em que esses se encontram. Aqui nota-se que é fundamental a desconstrução de práticas e escutas tidas como "normais", pois é justamente aqui que a migração coloca em xeque os pressupostos dados. Nesse sentido, é relevante apontarmos considerações sobre como as noções de raça, cultura e gênero podem operar nos discursos das políticas públicas.

Centramos aqui na figura do imigrante e consideramos as relações de gênero não somente no sujeito, mas como as normas hegêmonicas de sexualidade colaboram para práticas migratórias, como no caso das travestis entrevistadas.

Partindo da análise do fetichismo, discursos sobre raça e cultura são vistos como cruciais ao debate sobre imigração, e, mais precisamente, quando o imigrante aparece como o "outro fetichizado" em discurso. Raça, gênero e cultura são construções fluidas que variam de acordo com os diferentes contextos sócio-políticos. Entretanto, é na fixidez histórica de alguns outros específicos que discursos sobre raça e cultura são (re)produzidos tendo funções específicas, por exemplo, as modalidades do imaginário social apresentadas nos fragmentos levantados. Esse apontamento é fundamental para ser levado em consideração para a análise dessas categorias da biopolítica econômica.

Assim, nesse sentido, raça refere ao regime de diferenças, que produz outros específicos, socialmente e politicamente localizados, produzidos e reproduzidos na história. Racismo, como resumido por Balibar (1991) é

Um verdadeiro "fenômeno social total" - se inscreve em práticas (formas de violência, desprezo, intolerância, humilhação e exploração), em discursos e representações que são tantas elaborações intelectuais do fantasma da profilaxia e segregação (a necessidade de purificar o corpo social, para preservar a "si próprio", ou "nossa" identidade de todas as formas de mistura, miscigenação e invasão) e que são articuladas ao redor do estigmata da alteridade (otherness) (nome, pele, cor, práticas religiosas) ${ }^{4}$. (pp. 17-18)

Balibar (2002) nesse sentido questiona as novas formas de racismo, e mais especificamente como discursos sobre "cultura" funcionam aqui.

É um racismo em que o tema dominante não é o da hereditariedade biológica mas da não superação (insurmountability) das diferenças culturais, um racismo o qual, à primeira vista, não postula a superioridade de certos grupos ou povos em relação

\footnotetext{
4 "a true 'total social phenomenon' - inscribes itself in practices (forms of violence, contempt, intolerance, humiliation and exploitation), in discourses and representations which are so many intellectual elaborations of the phantasm of prophylaxis or segregation (the need to purify the social body, to preserve "one's own" or "our" identity from all forms of mixing, interbreeding or invasion) and which are articulated around stigmata of otherness (name, skin colour, religious practices)."
} 
a outros mas "apenas" a nocividade em abolir fronteiras, a incompatibilidade de estilos de vida e tradições, em resumo, o que P. A. Taguieff corretamente chamou de um racismo diferencialista. ( $\mathrm{p}$. 21, tradução nossa) $)^{5}$.

Nessa direção, é possível questionar como "raça" e "cultura" são colocados e utilizados no discurso. De fato, Zizek (1998) comenta

Sem o real do gozo, o Outro permanece em última instância uma ficção, um sujeito puramente simbólico de racionalização estratégica exemplificada na "teoria da escolha racional". Por essa razão, se é tentado a substituir o termo "multiculturalismo" por "multiracismo": o multiculturalismo suspende o centro traumático do Outro, reduzindo-o uma entidade folclórica asséptica. (p. 168, tradução nossa) ${ }^{6}$

Zizek (1998) continua citando Michaels (1992, pp. 682-85): "Nosso senso de cultura é caracteristicamente tomado (meant) para deslocar (displace) raça, mas . . . Cultura se tornou uma maneira de continuar ao invés de repudiar o pensamento racial"' (p. 168). ${ }^{7}$

Esses são aspectos cruciais, ou seja, raça e cultura são termos usados de uma maneira específica e nesse sentido é possível ver a substituição de raça por cultura, mantendo os mesmos regimes de diferença, nesse caso, a reiteração de posições específicas do outro. Isso, na intersecção com gênero (e outras categorias sociais), produz determinados efeitos discursivos, como os apontados anteriormente nos exemplos levantados, mas também podemos levantar outros efeitos, por exemplo, podemos conceitualizar o imigrante como "feminizado" no discurso, ou seja, discursos sobre o "feminino" transpostos para os imigrantes. Por outro lado, especificidades de gênero,

5 "It's a racism whose dominant theme is not biological heredity but the insurmountability of cultural differences, a racism which, at first sight, does not postulate the superiority of certain groups or peoples in relation to others but 'only' the harmfulness of abolishing frontiers, the incompatibility of life-styles and traditions, in short, it is what P. A. Taguieff has rightly called a differentialist racism".

6 "Without the real of jouissance, the Other remains ultimately a fiction, a purely symbolic subject of strategic reasoning exemplified in the "rational choice theory". For that reason, one is even tempted to replace the term "multiculturalism" with "multiracism": Multiculturalism suspends the traumatic kernel of the Other, reducing it to an aseptic folklorist entity".

7 "Our sense of culture is characteristically meant to displace race, but... culture has turned out to be a way of continuing rather than repudiating racial thought". particularmente relacionados às mulheres e minorias sexuais, são fundamentais para a análise das relações de poder em relação à imigração.

Os exemplos trazidos nesse artigo ilustram a importância em se considerar as dinâmicas de poder nas categorias sociais de raça, gênero, classe e outras, tanto para as intervenções diretas com imigrantes, quanto para a produção de políticas públicas e para evitar a reprodução de desigualdades sociais. Nos fragmentos levantados, a posição do outro do imigrante é vista em relação à diferença que, nos casos, muitas vezes não são considerados ou, quando o são, o tema exclusão faz-se mais evidente, como nos casos das migrações citadas realizadas pelas travestis. E aqui temos novamente a oscilação entre a celebração da igualdade e por outro lado a celebração do outro e do multiculturalismo. Dessa forma, de um lado há o risco da anulação das diferenças e por outro há o risco da fetichização do sujeito, visto como exótico, diferente.

Nessa direção, tomando a fetichização do outro a partir da posição simbólica do estranho (estrangeiro), podemos apontar alguns dos aspectos que podem criar espaços para outras posições. O caráter autoevidente da diferença (Badiou, 2001) aponta para a necessidade em situar historicamente e politicamente a posição do imigrante e revisar como os discursos sobre raça e cultura são construídos e reproduzidos nessas dinâmicas. Como Ahmed (2000) aponta, o entendimento do imigrante como stranger (estrangeiro/desconhecido) não é suficiente para abarcar as complexidades das histórias, "não apenas pelo deslocamento das pessoas, mas também pela demarcação dos lugares e espaços de pertencimento" (p. 79). Ahmed ressalta a importância em olhar as "determinações históricas dos padrões de estrangeiramento (estrangement)" (p. 79) sem assumir uma ontologia do estrangeiro (stranger).

Estas são análises críticas importantes para serem consideradas nas políticas públicas, assim como nos discursos cotidianos, que oscilam entre a celebração do outro e a política da igualdade, estratégias que são politicamente importantes, mas que em alguns momentos podem obscurecer o contexto político e as lutas sociais, mantendo o imigrante na reificada posição que ocupa.

Dessa forma, torna-se crucial identificar a posição simbólica que os imigrantes ocupam no discurso e como gênero, classe e outras categorias sociais intersectam com essa posição, que são produzidas e reproduzidas nas estruturas políticas e sociais, reiterando discursos que oscilam entre vítima, exótico e ameaça, reiterando a posição fetichisada do outro. 


\title{
The other: a critical analysis of discourses on immigration and gender
}

\begin{abstract}
This article aims to develop a critical analysis of discourses on immigration and the position that some immigrants occupy in the social discourse. The focus is on the minimization process of some groups, highlighting the gender issue and the intersections between sexuality, ethnicity and class, as in the tradition of feminist and post-colonial critical studies. In this regard, we examine some fragments of cases of recently arrived immigrants in a large urban center, São Paulo, Brazil. The position in relation to the immigrant, as a representative of otherness, allowed us to raise some considerations, based on the theory of psychoanalysis, Foucault and feminist and anti-racist studies. In the presented cases, it is noted that the immigration process itself is often not taken into account in the relation with the immigrant, which can naturalize the social differences as individual traits pathologized when not criminalized. Various positions within the social imaginary are highlighted and experienced in the relationship with immigrants. Although with its specificities, one can note that a series of speeches on immigrants are continuously repeated, often referring to them as victims, threats or exotic beings. From this discursive reiteration, we analyze how the other is constituted in this discourse, often appearing as a fetishized other. This analysis aimed to promote critical points for interventions and public policies.
\end{abstract}

Keywords: immigration, gender, psychoanalysis, discourse analysis, critical theories

\section{L'autre: une analyse critique des discours sur l'immigration et le genre}

Résumé: Cet article vise à développer une analyse critique des discours sur la thématique de l'immigration. On met l'accent sur les processus de disqualification de certains groupes sociaux, soulignant la question du genre en tenant compte des intersections entre le genre, la race et la classe, selon la tradition d'études critiques féministes et postcoloniales. En ce sens, nous examinos certains fragments des cas d'immigrants nouveaux arrivants au centre urbain de São Paulo, Brésil. La position par rapport au immigrant, en tant que répresentant de l'altérité, nous a permis de faire plusieurs considérations à partir du cadre théorique de la psychanalyse, de l'œuvre de M. Foucault et d'études féministes et antiracistes. Sur la base des cas présentés, nous pouvons affirmer que même si l'on prend en compte les caractéristiques spécifiques de chaque histoire, les différences sociales sont naturalisés comme traits individuels pathologisés ou criminalisés, et divers opinions au sein de l'imaginaire social sont mis en évidence et expérimentés dans le traitement des immigrants. Toute une série des discours sur l'immigrant sont renouvelés et répétés en les plaçant la position de «victimes», «menaces», «exotiques». En partant de cette réitération discursive, nous allons analyser comment l'idée de l'autre se constitue et réapparaît dans sa forme fétichisé. L'objectif de cette analyse a été de promouvoir points critiques pour les interventions et les politiques publiques.

Mots cles: immigration, le genre, la psychanalyse, l'analyse du discours, théories critiques.

\section{El otro: análisis crítico de los discursos sobre la inmigración y el género}

Resumen: Este artículo tiene como objetivo desarrollar un análisis crítico de los discursos sobre la inmigración y la posición de que ocupan algunos inmigrantes en el discurso social. El trabajo se centrará en los procesos de descalificación de algunos grupos, destacando el tema de género, sin embargo, teniendo en cuenta las intersecciones entre sexualidad, raza y clase, de acuerdo con la tradición de estudios críticos feministas y postcolonial. En este sentido, echemos un vistazo a algunos fragmentos de los casos de los inmigrantes recién llegados a un gran centro urbano, São Paulo. La posición en relación al inmigrante, como representante de la alteridad, del otro, nos permite plantear algunas consideraciones en la confluencia del pensamiento del Psicoanálisis, de Foucault y de los estudios feministas y antirracistas. En los casos presentados, se observa que muchas veces no tiene en cuenta el proprio proceso de inmigración en relación al inmigrante, lo que pueden naturalizar las diferencias sociales como rasgos individuales de patologia y, muchas veces, del crimen. De esta manera, se destacan diversas posiciones dentro del imaginario social con respeto a los inmigrantes. Aunque con sus especificidades, se puede señalar que una serie de discursos acerca de los inmigrantes reafirma a menudo la posición de víctima, amenaza o exótico. De esta repetición discursiva, se analiza cómo el otro está constituido en ese discurso ya que a menudo aparece como un fetiche, así se busca en dicha análisis la promoción de intervenciones y políticas públicas.

Palabras clave: inmigración, género, psicoanálisis, análisis del discurso, teorías críticas. 


\section{Referências}

Ahmed, S. (2000). Strange encounters: Embodied others in post-coloniality. London: Routledge.

Badiou, A. (2001). Ethics - an essay on the understanding of evil. London: Verso. Balibar, E. (1991). Is there a neo-racism? In E. Balibar, \& I. Wallerstein (Ed.), Race, nation, class. ambiguous identities (pp. 17-28). Verso: London.

Butler, J. (1998). Problemas de gênero: feminismo e subversão da identidade. Rio de Janeiro, RJ: Civilização Brasileira.

Butler, Judith (1999). Gender Trouble: feminism and the subversion of identity. Londres: Routledge.

Burman, E. (2000). Method, measurement and madness. In L. Holzman \& Morss, J. (Org.), Postmodern psychologies, societal practice and political life (pp. 49-79). Londres: Routledge.

Chatelard, D. S. (2001). Algumas considerações sobre o termo afânise a partir de E. Jones e J. Lacan. Ágora, 4(2), 51-59. Recuperado de http://dx.doi.org/10.1590/S151614982001000200004

Chomsky, N. (1991). Deterring democracy. London: Verso.

Engel, Magali (1997). Psiquiatria e feminilidade. In M. Del Priore (Ed.), História das mulheres no Brasil (pp. 322361). São Paulo, SP: Contexto.

Foucault, M. (1991). Discipline and punishment: The birth of the prison. Londres: Penguin Books.

Foucault, M. (2002). The archaeology of knowledge. London: Routledge. (Trabalho publicado originalmente em 1969)

Foucault, M. (1998). The will to knowledge - the history of sexuality I. London: Penguin Books.

Frosh, S. (1995). Time, space and otherness. In S. Pile \& N. Thrift (Eds.), Mapping the subject - geographies of cultural transformation (pp. 291-308). London: Routledge.

Gilroy, P. (2000). Entre campos: nações, culturas e o fascínio da raça. São Paulo, SP: Annablume.

Gordo-López, A. J. (1995). Un análisis cualitativo y discursivo de los programas clínicos de cambio de sexo: transexualismo, "travestis" y otros objetos límite. Revista de psicología social aplicada, 5(1/2), 127-146.

Grosz, E. (1990). Jacques Lacan - A feminist introduction. London: Routledge.

Junqueira, R. (2007). Homofobia: limites e possibilidades de um conceito em meio a disputas. Bagoas, 1(1), 1-22.

Lacan, J. (1998). Subversão do sujeito e dialética do desejo no inconsciente freudiano. In J. Lacan, Escritos. Rio de Janeiro, RJ: Jorge Zahar. (Trabalho original publicado em 1966)

Lacan, J. (2008). O seminário. Livro 16: de um Outro ao outro. Rio de Janeiro, RJ: Jorge Zahar. (Trabalho original publicado em 1968-1969)
McClintock, A. (1995). Imperial leather - race, gender and sexuality in the colonial contest. London: Routledge.

Mountian, I. (2013). Cultural ecstasies: Drugs, gender and social imaginary. Londres: Routledge.

Mountian, I. (2012). Relatório de pesquisa. Travestilidade e envelhecimento. Pesquisa. UFMG. Apoio CNPQ.

Mountian, I., \& Gonzalez, E. C. (2011). Race, class and affirmative action in Brazil: Reflections from a feminist perspective. Feminism \& Psychology: Special Feature: Feminisms and Psychologies in the Latin American context (pp. 240-248). London: Sage.

Neill, C. (2011). Lacanian ethics and the assumption of subjectivity. Basingstoke: Palgrave Macmillan.

Parker, I. (2011). Lacanian psychoanalysis. Londres: Routledge.

Parker, I. (2002). Discursive resources in discourse unit. In Discourse Analysis Online. Retrieved from www.shu. ac.uk/daol

Parker, I. (1992). Discourse dynamics - critical analysis for social and individual psychology. London: Routledge.

Pateman, C. (1993). O contrato sexual. Rio de Janeiro, RJ: Paz e Terra

Ramos, C. (2009). Do multiculturalismo como criação de novos targets: a política de identidades e a inscrição totalitária do gozo. A Peste: revista de psicanálise e sociedade, 1(1), 49-63.

Rohden, F. (2003). A construção da diferença sexual na medicina. Cadernos de Saúde Pública, 19(Sup. 2), 201212

Rosa, M. D. (2013). Psicanálise implicada vicissitudes das práticas clinicopolíticas. Revista da Associação Psicanalítica de Porto Alegre, 41, 29-40.

Rosa, M. D., \& Cerruti, M. (2014). Da rivalidade à responsabilidade: reflexões sobre justica restaurativa a partir da psicanálise. Psicologia USP, 25(1), 13-19.

Silva, T. T. (2000). Identidade e diferença: a perspectiva dos estudos culturais. Petrópolis, RJ: Vozes.

Verhaeghe, P. (1997). Does the woman exist? - from Freud's hysteric to Lacan's Feminine. London: Rebus Press.

Yuval-Davis, N. (1997). Gender \& Nation. Londres: Sage

Žižek, S. (2005). Multiculturalismo, ou a lógica cultural do capitalismo multinacional. In C. I. Dunker \& J. A. Prado (Orgs.), Žižek crítico: política e psicanálise na era do multiculturalismo (pp. 11-45). São Paulo, RJ: Hacker. (Trabalho publicado originalmente em 1997)

Žižek, S. (1998). Love thy neighbour. No thanks. In C. Lane (Ed.), The psychoanalysis of race. New York: Columbia University Press.

Recebido: $27 / 01 / 2015$

Revisado: 09/02/2015

Aceito: 15/02/2015 